Original Article

\title{
The effect of segmental weight of prosthesis on hemodynamic responses and energy expenditure of lower extremity amputees
}

\author{
Akmer Mutlu, PT, PhD ${ }^{1)^{*}}$, Mohammad Dawood Kharooty, MD, MScli), Yavuz Yakut, PT, PhD ${ }^{1)}$ \\ 1) Department of Physiotherapy and Rehabilitation, Faculty of Health Sciences, Hacettepe University: \\ Ankara 06100, Turkey
}

\begin{abstract}
Purpose] The aim of this study was to investigate the effect of segmental weight of the prosthesis on hemodynamic responses and energy expenditure in lower extremity amputees. [Subjects and Methods] Thirteen patients with a mean age of $44 \pm 15.84$ years and with unilateral transtibial, transfemoral and Syme's amputation were included to the study. The difference between the lightest and the heaviest prosthesis, $250 \mathrm{~g}$ used as the weight. All the patients completed the measurements first without weight and then with $250 \mathrm{~g}$ weight on the ankle joint. The blood pressure and heart rate of the patients were recorded before and after Six Minute Walk Test (6MWT) and 10 stairs up \& down stairs test. Physiological Cost Index was used to calculate the energy expenditure. [Results] Heart rate and energy expenditure increased significantly when without weight and with weight results compared. [Conclusion] We conclude that the segmental weight of the prosthetic limb has a significant effect on the heart rate and energy expenditure but has no effect on the systolic and diastolic blood pressure of lower limb amputees. In order to generalize our results to lower limb amputees, more patients need to be included in future studies. Key words: Amputation, Prosthesis, Hemodynamic responses
\end{abstract}

(This article was submitted Oct. 11, 2016, and was accepted Dec. 21, 2016)

\section{INTRODUCTION}

Amputation is the surgical removal of an external part of the body, most often a limb or a part of it, as a form of treatment ${ }^{1)}$. Amputation not only requires additional funds for rehabilitation, but also prosthetic creation, management and maintenance ${ }^{2}$. Compared to normal ambulation, the energy costs for prosthetic ambulation are much higher increased energy. The energy required for ambulation in lower extremity amputees are as follows: unilateral trans-tibial amputation 40-60\%, unilateral trans-femoral amputation 90 to $120 \%$, bilateral trans-tibial amputation $60-100 \%$ and bilateral trans-femoral amputation $>200 \%$ above the normal and this energy demand becomes even higher if additional significant comorbidities exist ${ }^{3)}$. Generally, patients with trans-tibial amputation, whether unilateral or bilateral, cope better than those who undergo above-knee amputation. The level of the amputation is also a key determinant for successful ambulation. Rehabilitation of a patient who has undergone amputation is an intricate process, as several factors determine successful ambulation with a limb prosthesis. These factors include pre-existing pulmonary disease, cardiovascular disease, peripheral vascular disease, diabetes, hypertension, hyperlipidemia, the status of the other limb and functional level prior to amputation ${ }^{3}$.

The aim of this study was to investigate the effect of segmental weight of the prosthesis on hemodynamic responses and energy expenditure in lower extremity amputees. It is known that with the ankle attachment, that the articifial foot prosthetics weight could differ. Therefore, The following hypotheses were formed for this research study: 1) The segmental weight changes of prosthesis have a significant effect on the hemodynamic responses and energy expenditure of lower limb amputees and 2) When the segmental weight is increased the hemodynamic responses and energy expenditure of lower limb amputees are increased. 


\section{SUBJECTS AND METHODS}

The study design was a cross-sectional prospective study. The subjects were patients who had undergone lower limb amputation and who had been referred to the Prosthetics Unit of the Department of Physiotherapy and Rehabilitation of Hacettepe University for a new prosthesis to be designed or the current prosthesis to be repaired as well as for evaluation for the physiotherapy and rehabilitation programme. A total of 13 lower limb amputees aged 18 to 65 years who had undergone unilateral Syme's (1 patient), transtibial (11 patients) or transfemoral (1 patient) amputation and were able to walk independently, had no need for assistance and volunteered to participate were included in this study. All subjects had normal blood pressure and heart rate. Exclusion criteria were age below 18 years or above 65 years, hypertension, bilateral lower limb amputation, wheelchair or other aid use, cardiac and pulmonary disorders, and lack of cooperation. One subject was excluded due to severe lower limb pain while walking. With the ankle attachment, it is determined that the lightest articifial foot prosthetics was $430 \mathrm{~g}$ and the heaviest was $680 \mathrm{~g}$. The difference between the weight of the lightest and the heaviest prosthesis used was $250 \mathrm{~g}$. Thus, $250 \mathrm{~g}$ was used as the segmental weight. All the patients completed the measurements first without weight and then with a $250 \mathrm{~g}$ weight placed on the ankle of the prosthesis. All subjects were informed about the study and written consent was obtained. Hacettepe University Noninterventional Clinical Researchs Ethics Committee approved the study (GO 14/33) and the study took place between February 2014 and July 2014.

The following methods, evaluations and procedures were used for this study: 1) General evaluation: General information and medical background data of the subjects were collected by means of an interview as well as from their medical files. Name, age, the age of amputation, level of amputation, years of prosthesis use were recorded. 2) Blood pressure: The blood pressure in terms of systolic pressure (SBP) and diastolic pressure (DBP) was measured with a sphygmomanometer before and after functional performance tests, with and without the study weight ${ }^{4}$. 3) Heart rate: The heart rate was determined with the radial pulse method by placing the index and middle fingers on the correct spot to feel the pulse and counting the number of beats per minute. The heart rate of all subjects was counted before and after the functional performance tests, with and without the study weight ${ }^{4}$. Double product of the patients were determined by consisting of the systolic blood pressure (SBP) multiplied by the pulse rate (PR), is an index of myocardial oxygen consumption ${ }^{4}$. 4) Energy Expenditure Evaluation: The easy-to-use Physiological Cost Index [(walking heart rate) - (resting heart rate) / (walking speed)] was used to determine energy expenditure. The patient was asked to sit on a chair for 10 minutes before starting the 6 minute walk test (6MWT) and the heart rate was determined. The patient was then asked to stand up and start walking when ready. The chronometer was started as soon as the patient started walking. The patient was asked to sit on the chair again at the end of 6 minutes and the heart rate was measured again. The walking distance was recorded so that the walking speed could be calculated. After the patient had rest for 15 minutes again, the patient repeated the 6MWT, this time with added weight. Once all the parameters were ready, the Physiological Cost Index indicating the energy expenditure was calculated separately for with and without the study weight for a possible comparison ${ }^{5)}$. 5) Functional Performance Tests: Six-minute Walk Test (6MWT): 6MWT is used to measure functional capacity, walking distance ability and endurance ${ }^{6}$. The distance of the $6 \mathrm{MWT}$ reflects whether a person could practically ambulate in the community. The reliability of the 6MWT has been established for lower extremity amputees with a test-retest reliability greater than $0.9^{7}$. A 20 -meter section of the indoor corridor was demarcated for the 6MWT. A start and end line was indicated for each $60 \mathrm{~m}$ lap and turnaround points were marked on the floor using colored tape. The participant was asked to walk straightly as far as possible for six minutes in the demarcated corridor and to turn back at the end of each lap. The chronometer was started when the participant stepped over the start line. The evaluator provided standardized encouragement to the patient after each minute. The participant was informed to stop before the test was finished if he/she felt uncomfortable and was unable to complete the full six minutes. In such cases, the test was terminated and repeated later on. At the end of test, the total distance was measured in meters and recorded. The patient sat on the chair near the starting point and the blood pressure and heart rate were measured. The subject was given an opportunity to rest for 10 minutes before the next test was started. The test was repeated with the $250 \mathrm{~g}$ added weight. 10 Stairs Up \& Down Test: The ten stairs up \& down test is usually used to strengthen the lower extremity muscles and improve the balance of lower limb amputees $^{8)}$. Before the test, a trial was performed to make sure that the subjects could complete the test. The blood pressure and pulse rate were determined before starting the test. Timing began on the signal to start and ended when the participant returned to the ground level with both feet. We first asked the subjects to go up \& down 10 stairs, without the weight. We started the stopwatch when the subject started to ascend the stairs and stopped it when the descent was completed. The blood pressure and heart rate were recorded. After ten minutes of rest time, the test was repeated with the $250 \mathrm{~g}$ added weight.

We used SPSS version 18 for data analysis. All demographic as well as dependent variables are presented by mean values, standard deviation (SD) and minimal and maximal values. Demographical features of the subjects were compared. The 6MWT distance, ten-stairs up \& down test duration with and without weight were compared. The same comparison was performed for the blood pressure and heart rate before and after, 6MWT, the ten-stairs up \& down test with and without weight. Physiological Cost Index of Patients without weight and with weight was also compared. We used the Paired Samples t-test for statistical analysis. This test is a parametric test, showing $t$ and $p$ values. The homogeneity of all variables was determined with the Kolmogorov-Smirnov test, a nonparametric test. The Paired Samples t-test was used because of the homogeneity of the parameters. Analysis within the dependent variables was also performed to show any differences in the variables with and 
Table 1. The comparison of distance and duration in functional performance tests without weight and with weight

\begin{tabular}{lcccc}
\hline Functional Performance Tests $(\mathrm{n}=13)$ & Mean \pm SD & Minimum & Maximum & $\mathrm{t}$ \\
\hline 6MWT without weight $(\mathrm{m})$ & $380.0 \pm 79.8$ & 219.0 & 542.5 & \multirow{3}{*}{$3.346^{*}$} \\
6MWT with weight $(\mathrm{m})$ & $365.1 \pm 82.3$ & 218.0 & 533.3 & \\
10 stairs up \& down without weight (sec) & $17.6 \pm 6.8$ & 10.0 & 31.0 & -0.670 \\
10 stairs up \& down without weight (sec) & $17.9 \pm 6.8$ & 9.0 & 30.0 & \\
\hline n: number of patients; 6MWT: 6 minute walk test; SD: standard deviation; m: meter, sec: second, Statistically significant, \\
p $<0.05$
\end{tabular}

Table 2. Comparison of hemodynamic responses for $6 \mathrm{MWT}$

\begin{tabular}{|c|c|c|c|c|}
\hline $6 \mathrm{MWTB}(\mathrm{n}=13)$ & & & Mean \pm SD & Mean diff \pm SD \\
\hline \multirow{4}{*}{$\begin{array}{l}\text { HR } \\
\text { (bpm) }\end{array}$} & \multirow{2}{*}{ Before } & without weight & $75.0 \pm 8.7$ & \multirow{2}{*}{$-1.5 \pm 3.6$} \\
\hline & & with weight & $77.7 \pm 10.1$ & \\
\hline & \multirow{2}{*}{ After } & without weight & $80.9 \pm 9.0$ & \multirow{2}{*}{$-3.1 \pm 4.5$} \\
\hline & & with weight & $83.9 \pm 8.9$ & \\
\hline \multirow{4}{*}{$\begin{array}{l}\text { SBP } \\
(\mathrm{mmHg})\end{array}$} & \multirow{2}{*}{ Before } & without weight & $116.5 \pm 12.0$ & \multirow{2}{*}{$0.4 \pm 3.8$} \\
\hline & & with weight & $116.2 \pm 11.9$ & \\
\hline & \multirow{2}{*}{ After } & without weight & $116.0 \pm 11.2$ & \multirow{2}{*}{$-1.9 \pm 3.3$} \\
\hline & & with weight & $117.7 \pm 12.4$ & \\
\hline \multirow{4}{*}{$\begin{array}{l}\text { DBP } \\
(\mathrm{mmHg})\end{array}$} & \multirow{2}{*}{ Before } & without weight & $76.5 \pm 8.8$ & \multirow{2}{*}{$1.5 \pm 5.6$} \\
\hline & & with weight & $75.0 \pm 8.7$ & \\
\hline & \multirow{2}{*}{ After } & without weight & $74.6 \pm 8.8$ & \multirow{2}{*}{$0.0 \pm 2.0$} \\
\hline & & with weight & $74.6 \pm 9.0$ & \\
\hline \multirow{4}{*}{$\begin{array}{l}\text { DP } \\
\text { (mmHg.bpm) }\end{array}$} & \multirow{2}{*}{ Before } & without weight & $8,600.0 \pm 1,540.5$ & \multirow{2}{*}{$-157.7 \pm 472.6$} \\
\hline & & with weight & $8,757.7 \pm 1,650.4$ & \\
\hline & \multirow{2}{*}{ After } & without weight & $9,406.2 \pm 1,683.1$ & \multirow{2}{*}{$-508.5 \pm 589.1$} \\
\hline & & with weight & $9,914.6 \pm 1,750.6$ & \\
\hline
\end{tabular}

6MWT: 6 minute walk test; n: number of patients; SD: standard deviation; mean diff: Mean difference; HR: heart rate; bpm: beats per minute; SBP: systolic blood pressure; DBP: diastolic blood pressure; DP: Double Product; $\mathrm{mmHg}$ : millimeters of mercury, ${ }^{*}$ Statistically significant, $\mathrm{p}<0.05$

without weight and before and after the 6MWT and ten stairs up \& down test. Similarly, the Paired Sample t-test was used for normally distributed data. The significance level was set at the $\mathrm{p}<0.05$ level with $\mathrm{p}<0.01$ showing strong significance.

\section{RESULTS}

A total of 13 patients with a mean age of $44.00 \pm 15.85$ years ( $\min =18-\max =65$ years) were included in the study. Amputation age was $21.62 \pm 16.40$ years $(\min =1-\max =47$ years). Year of the prosthetics use was $15.62 \pm 14.16$ years $(\mathrm{min}=1-$ $\max =42$ years).

The distance walked in 6MWT and the duration in 10 stairs up \& down tests, with weight and without weight was compared and presented in Table 1. There was significant difference between the distance covered by subjects without weight and with weight $(\mathrm{t}=3.346, \mathrm{p}=0.006)$.

Hemodynamic responses of the patients for 6MWT and 10-stairs up \& down without weight and with weight before the tests and after the tests are presented in Tables 2 and 3. The only significant difference was between the heart rate values and double product after 6 MWT $(\mathrm{t}=-2.446, \mathrm{p}=0.031)(\mathrm{t}=-3.112, \mathrm{p}=0.009)$ and the heart rate values after 10 -stairs up \& down test, with and without weight $(\mathrm{t}=3.138, \mathrm{p}=0.009)$. The results for SBD and DBP did not show any significant difference.

In addition, comparison of hemodynamic responses were made between before and after 6MWT for non-weight as well as between before and after for with weight. The results indicated that only heart rate showed significance for before-after comparison without weight $(\mathrm{t}=-4.854, \mathrm{p}=0.000)$ and before-after comparison with weight $(\mathrm{t}=-4.757, \mathrm{p}=0.000)$. The comparison for SBD and DBP did not show any significant difference. Comparison of hemodynamic responses were made between before and after 10 stairs up \& down for non-weight as well as between before and after for with weight. The results indicated that only heart rate showed significance for before-after comparison without weight $(\mathrm{t}=-2.525, \mathrm{p}=0.027)$ and before-after comparison with weight $(\mathrm{t}=-5.095, \mathrm{p}=0.000)$. The comparison for SBD and DBP did not show any significant difference. The 
Table 3. Comparison of hemodynamic responses for 10 stairs up and down

\begin{tabular}{|c|c|c|c|c|c|}
\hline \multicolumn{3}{|c|}{10 stairs up \& down $(n=13)$} & \multirow{2}{*}{$\begin{array}{r}\text { Mean } \pm \text { SD } \\
69.1 \pm 15.4\end{array}$} & \multicolumn{2}{|l|}{ Mean diff \pm SD } \\
\hline \multirow{4}{*}{$\begin{array}{l}\text { HR } \\
\text { (bpm) }\end{array}$} & \multirow{2}{*}{ Before } & without weight & & \multirow{2}{*}{$-8.3 \pm 18.9$} & \\
\hline & & With weight & $77.4 \pm 9.5$ & & \\
\hline & \multirow{2}{*}{ After } & without weight & $80.9 \pm 8.8$ & \multirow{2}{*}{$-3.6 \pm 4.2$} & $*$ \\
\hline & & With weight & $84.5 \pm 8.7$ & & \\
\hline \multirow{4}{*}{$\begin{array}{l}\text { SBP } \\
(\mathrm{mmHg})\end{array}$} & \multirow{2}{*}{ Before } & without weight & $115.4 \pm 12.2$ & \multirow{2}{*}{$-1.2 \pm 3.0$} & \\
\hline & & With weight & $116.5 \pm 13.1$ & & \\
\hline & \multirow{2}{*}{ After } & without weight & $115.4 \pm 12.2$ & \multirow{2}{*}{$-3.1 \pm 5.6$} & \\
\hline & & With weight & $118.5 \pm 13.5$ & & \\
\hline \multirow{4}{*}{$\begin{array}{l}\text { DBP } \\
(\mathrm{mmHg})\end{array}$} & \multirow{2}{*}{ B efore } & without weight & $76.5 \pm 9.4$ & \multirow{2}{*}{$0.4 \pm 1.4$} & \\
\hline & & With weight & $76.2 \pm 9.8$ & & \\
\hline & \multirow{2}{*}{ After } & without weight & $75.5 \pm 9.1$ & \multirow{2}{*}{$-0.6 \pm 2.2$} & \\
\hline & & With weight & $76.2 \pm 9.8$ & & \\
\hline \multirow{4}{*}{$\begin{array}{l}\text { DP } \\
\text { (mmHg.bpm) }\end{array}$} & \multirow{2}{*}{ Before } & without weight & $7,994.2 \pm 2,173.2$ & \multirow{2}{*}{$-1,072.3 \pm 2,513.5$} & \\
\hline & & with weight & $9,066.5 \pm 1,777.8$ & & \\
\hline & \multirow{2}{*}{ After } & without weight & $1,629.0 \pm 451.8$ & \multirow{2}{*}{$297.7 \pm 856.7$} & \\
\hline & & with weight & $1,777.8 \pm 493.1$ & & \\
\hline
\end{tabular}

SD: standard deviation; n: number of patients; Mean diff: mean difference; HR: heart rate; bpm: beats per minute; SBP: systolic blood pressure; DBP: diastolic blood pressure; DP: Double Product; mmHg: millimeters of mercury, ${ }^{*}$ Statistically significant, $\mathrm{p}<0.05$

Table 4. Physiological Cost Index of patients without weight and with weight paired samples test

\begin{tabular}{lccc}
\hline PCI $($ pulse $/ \mathrm{m})$ & Mean \pm SD & Mean diff \pm SD & \\
\hline Without weight & $79.6 \pm 8.8$ & $-2.9 \pm 4.5$ & $*$ \\
With weight & $82.6 \pm 8.6$ & & \\
\hline
\end{tabular}

PCI: Physiological Cost Index; pulse/m: pulse per minute; SD: standard deviation; Mean diff: mean difference; HR: heart rate; SBP: systolic blood pressure; DBP: diastolic blood pressure, ${ }^{*}$ Statistically significant, $\mathrm{p}<0.05$

difference between the physiological cost index of the patients with and without weight also showed significance $(\mathrm{t}=-2.342$, $\mathrm{p}=0.037$ ) (Table 4).

\section{DISCUSSION}

This study indicated that the weight of the prosthesis makes a significant difference on the heart rate and energy expenditure but not affect the blood pressure during the functional performance tests.

A total of 13 subjects completed our study that was based on the hypothesis that the weight of the prosthesis has an effect on the hemodynamic responses of lower limb amputees. Most similar studies discuss the effect of the added prosthesis mass on the kinematic and kinetic features of the gait cycle, oxygen and energy consumption. Some of these studies have also discussed the effect of weight and exercises on the heart rate and the stride and step lengths of lower limb amputees, but these studies provided no information on the systolic and diastolic pressures ${ }^{9-15)}$. The power analysis of our study revealed that 13 unilateral lower limb amputees would be adequate. Similar studies have involved 10-35 subjects.

The participants performed the 6MWT with $250 \mathrm{~g}$ weight added to their ankle. Three of the 13 subjects were able to go the same distance as without the added weight. Nine suffered a limitation of their walking distance when the weight was added to their prosthetic limb. One subject even went further when the weight was added to the prosthetic limb. When the weight was added, the walking distance were decreased. A previous study have reported no significant change between gait parameters such as stride and step lengths and stance and swing phase durations in both the prosthetic and intact extremities with alteration of the prosthetic mass ${ }^{16)}$. Although there have been studies comparing the effects of the prosthetic mass on oxygen consumption and gait efficiency, our study aimed to focus on hemodynamic responses of the patients with and without extra weight.

Lin-Chan ${ }^{17)}$ used prostheses with 3 different masses $(100 \%, 80 \%$ and $60 \%)$ and found that the prosthetic mass did not 
significantly change oxygen consumption or gait efficiency, although the relative exercise intensity significantly increased while stride frequency decreased with the $60 \%$ and $100 \%$ conditions, Hillery et al. ${ }^{18)}$ examined gait kinematics of patients with transfemoral amputation by adding $1.460 \mathrm{~kg}$ to the distal foot portion of the prosthesis and the stride frequency showed a small decrease ${ }^{18)}$. Gitter et al. ${ }^{19)}$ investigated the effects of adding masses of 0.68 and $1.34 \mathrm{~kg}$ to the center of mass of the prosthesis of 10 subjects with trans femoral amputation and they found no significant difference in stride length or frequency between the different masses. Czerniecki and colleagues ${ }^{20}$ studied the effect of different prosthetic masses by attaching $68 \mathrm{~g}$ and $1.34 \mathrm{~kg}$ to the center of mass at four different walking speeds in eight patients with transfemoral amputation. Their study showed no significant difference between the mass conditions at four different walking speeds as well as no difference in the kinematic and kinetic characteristics of gait when steel components were replaced with titanium. The hypothesis of another study was that a heavier prosthesis required more muscle activity to decelerate during the last part of swing phase and the authors found no difference in knee angle when titanium and steel trials were compared ${ }^{13)}$.

We did not find any significant statistical difference in systolic and diastolic blood pressures of the subjects under different conditions. There was some difference in the blood pressure of some subjects but this was not statistically significant. We can therefore conclude that the prosthetic weight does not have an effect on the blood pressure of lower limb amputees for our study. There are just few studies that describe the effect of exercise and prosthetic weight on the hemodynamic responses of the lower amputees. Our results was similar to Lin and Bose study, reported no difference in blood pressure before and after $6 \mathrm{MWT}^{7}$.

Hinton et al. ${ }^{21)}$ investigated the hemodynamic responses with ortho crutches and axillary crutches and found no significant difference between mean systolic and diastolic blood pressure between the two. The mean systolic blood pressure with unassisted ambulation was lower than with ortho crutches and axillary crutches. All our subjects could walk independently and did not use crutches and we found no difference in blood pressure before and after non-weight and with weight conditions.

Provencher et al. ${ }^{22)}$ reported that 6MWT increased the heart rate of the patients in their study. Vestering et al. ${ }^{23)}$ similarly found that the combined ergometer test increased the heart rate of lower limb amputees. We found that the heart rate was increased in all our tests indicating that both exercise and addition of weight increases the heart rate. Another study reported that the weight used has an effect on the heart rate in a study using three different mass conditions on subjects with transtibial amputation and found that the $100 \%$ condition increased the heart rate of the subject ${ }^{17)}$.

Lenka et al. ${ }^{24)}$ added four different weights $(200 \mathrm{~g}, 400 \mathrm{~g}, 600 \mathrm{~g}$ and $800 \mathrm{~g})$ to the lower limb amputees' prosthetic ankles and found increased heart rates with increasing weights. This result is similar to ours, indicating that the prosthetic weight influences the heart rate with increased heart rate with increased weight while walking and during the 10-step stair climb test. Sokhangoei et al. ${ }^{25)}$ compared the heart rates of an amputee group and control group and reported that the energy consumption amount and heart activity at any speed were higher in the amputee group. The heart rate of amputees was noted at different speeds and increasing speed was found to increase the heart rate. Our study showed similarity with Sokhangoei in terms of significance in heart rate and energy consumption. However, we did not have any control groups to compare the energy expenditure difference between amputees and healthy individuals.

Our study has proven that weight addition increased the heart rate during tests where the muscles need and use more oxygen and glucose from the blood. The decrease of blood $\mathrm{pH}$ below the normal range increases the heart rate. Thus, the heart delivers blood to the lungs and kidneys more quickly so that these organs can remove the waste from the body. The faster the muscles use energy and create waste, the faster the heart must pump the blood. As the patients induces greater metabolic demands for maintenance of balance and posture and for performing the functional performances.

Shiomi had five healthy men perform the stair climb test and determined that the heart rate was increased afterwards with a statistically significant difference ${ }^{26}$. We compared the heart rate before and after the test, first without adding a weight and then with the weight, and found a significant difference in the heart rate in both conditions. The weight increased the heart rate of amputees performing the 6MWT and 10-step stair climb tests.

We needed a sample of at least 13 subjects for this study but a larger sample might have been more informative. One limitation of the study is that we did not distribute the amputees into groups according to the level of amputation and compare the results accordingly due to limited number of participants from each level. In addition, we only added $250 \mathrm{~g}$ to the prosthesis and the effects of different weights on the hemodynamic response of amputees needs to be investigated.

We conclude that the segmental weight of the prosthetic limb has an significant effect on the heart rate and energy expenditure but has no effect on the systolic and diastolic blood pressure of lower limb amputees. When the segmental weight is increased the heart rate and energy expenditure of lower limb amputees are increased. The distances during the six-minute walk test were decreased with the weight. Examination of various factors such as age, exercise capacity, years of wearing a prosthesis, strength of lower limbs is also necessary. In order to generalize our results to lower limb amputees, more patients need to be included in future studies. The weight of the prosthesis and comparison with the unaffected/healthy lower extremity should be considered in the rehabilitation of amputees.

\section{Disclosure}

The paper is the original work of the authors and not copied from any other work. 


\section{Conflict of interest}

No funding or grants or equipment provided for the project from any source; no financial benefits to the authors.

\section{REFERENCES}

1) Udosen AM, Ngim N, Etokidem A, et al.: Attitude and perception of patients towards amputation as a form of surgical treatment in the University of Calabar teaching hospital, Nigeria. Afr Health Sci, 2009, 9: 254-257. [Medline]

2) Lefebvre KM, Lavery LA: Disparities in amputations in minorities. Clin Orthop Relat Res, 2011, 469: 1941-1950. [Medline] [CrossRef]

3) Sohal J, Arneja A, Sharma S: Oxygen supplementation facilitating successful prosthetic fitting and rehabilitation of a patient with severe chronic obstructive pulmonary disease following trans-tibial amputation: a case report. J Med Case Reports, 2010, 4: 410. [Medline] [CrossRef]

4) Brzezinski WA: Blood pressure. In: Clinical methods: the history, physical, and laboratory examinations. Boston: Butterworths, 1990 , pp 95-97.

5) ATS Committee on Proficiency Standards for Clinical Pulmonary Function Laboratories: ATS statement: guidelines for the six-minute walk test. Am J Respir Crit Care Med, 2002, 166: 111-117. [Medline] [CrossRef]

6) Reid L, Thomson P, Besemann M, et al.: Going places: does the two-minute walk test predict the six-minute walk test in lower extremity amputees? J Rehabil Med, 2015, 47: 256-261. [Medline] [CrossRef]

7) Lin SJ, Bose NH: Six-minute walk test in persons with transtibial amputation. Arch Phys Med Rehabil, 2008, 89: 2354-2359. [Medline] [CrossRef]

8) Schmalz T, Blumentritt S, Marx B: Biomechanical analysis of stair ambulation in lower limb amputees. Gait Posture, 2007, 25: 267-278. [Medline] [CrossRef]

9) Smith JD, Martin PE: Effects of prosthetic mass distribution on metabolic costs and walking symmetry. J Appl Biomech, 2013, 29: 317-328. [Medline] [CrossRef]

10) Ferris AE, Aldridge JM, Rábago CA, et al.: Evaluation of a powered ankle-foot prosthetic system during walking. Arch Phys Med Rehabil, 2012, 93: 19111918. [Medline] [CrossRef]

11) Chamlian TR, Melo AC: Functional assessment after lower limb amputation. Acta Fisiatr, 2008, 15: 49-58.

12) Chin T, Sawamura S, Fujita H, et al.: The efficacy of physiological cost index (PCI) measurement of a subject walking with an Intelligent Prosthesis. Prosthet Orthot Int, 1999, 23: 45-49. [Medline]

13) Bateni H, Olney SJ: Effect of the weight of prosthetic components on the gait of transtibial amputees. JPO, 2004, 16: 113-120.

14) Chin T, Kuroda R, Akisue T, et al.: Energy consumption during prosthetic walking and physical fitness in older hip disarticulation amputees. J Rehabil Res Dev, 2012, 49: 1255-1260. [Medline] [CrossRef]

15) Novacheck TF: The biomechanics of running. Gait Posture, 1998, 7: 77-95. [Medline] [CrossRef]

16) Hekmatfard M, Farahmand F, Ebrahimi I: Effects of prosthetic mass distribution on the spatiotemporal characteristics and knee kinematics of transfemoral amputee locomotion. Gait Posture, 2013, 37: 78-81. [Medline] [CrossRef]

17) Lin-Chan SJ, Nielsen DH, Yack HJ, et al.: The effects of added prosthetic mass on physiologic responses and stride frequency during multiple speeds of walking in persons with transtibial amputation. Arch Phys Med Rehabil, 2003, 84: 1865-1871. [Medline] [CrossRef]

18) Hillery SC, Wallace ES, McIlhagger R, et al.: The effect of changing the inertia of a trans-tibial dynamic elastic response prosthesis on the kinematics and ground reaction force patterns. Prosthet Orthot Int, 1997, 21: 114-123. [Medline]

19) Gitter A, Czerniecki J, Meinders M: Effect of prosthetic mass on swing phase work during above-knee amputee ambulation. Am J Phys Med Rehabil, 1997, 76: 114-121. [Medline] [CrossRef]

20) Czerniecki JM, Gitter A, Weaver K: Effect of alterations in prosthetic shank mass on the metabolic costs of ambulation in above-knee amputees. Am J Phys Med Rehabil, 1994, 73: 348-352. [Medline] [CrossRef]

21) Hinton CA, Cullen KE: Energy expenditure during ambulation with ortho crutches and axillary crutches. Phys Ther, 1982, 62: 813-819. [Medline]

22) Provencher S, Chemla D, Hervé P, et al.: Heart rate responses during the 6-minute walk test in pulmonary arterial hypertension. Eur Respir J, 2006, 27: 114-120. [Medline] [CrossRef]

23) Vestering MM, Schoppen T, Dekker R, et al.: Development of an exercise testing protocol for patients with a lower limb amputation: results of a pilot study. Int J Rehabil Res, 2005, 28: 237-244. [Medline] [CrossRef]

24) Lenka P, Biswas D, Kumar S: Impact of added prosthetic mass on metabolic cost and gait in persons with unilateral transtibial amputation. Indian J Biomech, 2013, 4: 63-69.

25) Sokhangoei Y, Abbasabadi A, Akhbari B, et al.: Investigating the relation of walking speed changes with the metabolic energy consumption index in traumatic unilateral below knee amputees. Pelagia Res Libr Eur J Exp Biol, 2013, 3: 173-177.

26) Shiomi T: Effects of different patterns of stairclimbing on physiological cost and motor efficiency. J Hum Ergol (Tokyo), 1994, 23: 111-120. [Medline] 